\title{
AVALIAÇÃO SIGNIFICATIVA NO PROCESSO DE APRENDIZAGEM ESCOLAR
}

Anaína Souza Santana•

\section{RESUMO}

O presente estudo, intitulado "Avaliação Significativa no Processo de Aprendizagem Escolar, objetivou compreender e analisar as práticas avaliativas e os significados a elas atribuídas por todos os envolvidos no processo de ensino e aprendizagem no Colégio Estadual Governador Luiz Viana Filho no município de Guanambi-Ba. O caminho metodológico percorrido teve uma abordagem qualitativa e quantitativa, dados foram coletados através da análise documental e questionários aplicados aos professores e alunos da instituição observada. O estudo baseia-se nas ideias de: Hoffmann $(2005,2008)$, Luckesi $(1998,2000,2005,2008)$, Villas Boas $(2004,2008)$ e outros. O trabalho traz, a trajetória histórica da avaliação, evidencia o sistema educacional brasileiro, as avaliações internas e externas características do ensino médio e reflete sobre a definição das palavras educar e educação. Destaca também o conselho de classe e a reunião de pais como práticas avaliativas que colaboram para um aprendizado inclusivo e reflexivo numa perspectiva dialógica e humanizada da avaliação. Os resultados, ainda parciais, denotam que os significados das práticas avaliativas vão além de aprovar ou reprovar e que o caminho para uma aprendizagem efetiva deve primar a divisão e o compartilhamento de responsabilidades por todos os envolvidos no processo de aprendizagem.

Palavras chave: Práticas Avaliativas. Reflexão. Responsabilidades. Significados.

- Mestranda em Ciências da Educação pela Fics - Facultad Interamericana de Ciencias Solciales. Asunción-PY. Contato: Email: anaina.1@hotmail.com (77) 999295356 


\section{INTRODUÇÃO}

Avaliar não é uma tarefa fácil, da mesma forma que ser avaliado também não se caracteriza como tal. Muitas são as discussões em torno da temática avaliação dentro e fora da instituição escolar.

A função educativa não é uma prerrogativa exclusiva da instituição escolar, mas passa também pela instituição familiar e se reflete na sociedade, visto que a formação do indivíduo contempla a sua autonomia e pleno exercício da cidadania.

A prática avaliativa é uma constante em todos os âmbitos sociais e culturais da sociedade e está presente na história da humanidade. A escola, por sua vez, estrutura suas ações pedagógicas tendenciando o cumprimento dos conteúdos programáticos, que teoricamente devem ser assimilados pelos alunos, utilizando-se das práticas avaliativas como instrumento de comprovação do sucesso da aprendizagem.

Luckesi (1996, p. 170) reflete sobre a forma tradicional de avaliar na atualidade ao diz que "o processo de avaliação servia para determinar em que medidas os objetivos educacionais estavam sendo alcançados, porém a prática continuou a ser baseada em provas e exames".

Neste sentido, Freitas (1995, p.63) diz que "a avaliação não se restringe a instrumentos de medição, mas acaba sendo configurada como instrumento de controle disciplinar, de aferição de atitudes e valores dos alunos".

Dentro deste debate, Vasconcelos (1998) evidencia a amplitude do conceito de avaliar ao dizer que:

A avaliação deve ser um processo abrangente da existência humana, que implica uma reflexão crítica sobre a prática no sentido de captar seus avanços e possibilitar uma tomada de decisões, acompanhando a pessoa em seu processo de crescimento". (VASCONCELOS 1998, p. 43)

Complementando a fala de Vasconcelos, a Lei 9394/96 (Lei de Diretrizes e Bases da Educação) em seu artigo 24, inciso V, sinaliza como deve ser a verificação do rendimento escolar "a) Avaliação contínua e cumulativa do desempenho do aluno, com prevalência dos aspectos qualitativos sobre os quantitativos, e dos resultados ao longo do período sobre o de eventuais provas finais". 
$\mathrm{Na}$ esfera educacional muitas são as discussões acerca da temática avaliação. Fato que desperta o interesse de vários estudiosos. O ensino médio, etapa final da educação básica, sente de forma mais acentuada o peso da avaliação, pois além da preocupação com as avaliações internas, os estudantes, precisam de uma atenção especial para as avaliações externas como seleções para vestibulares e ENEM (Exame Nacional do Ensino Médio).

Neste sentido, com foco nas avaliações, as práticas pedagógicas remetem aos estudos um cunho quantitativo voltado para assimilação de conteúdos e consequentemente para uma prática avaliativa que expressa o aprendizado em notas.

Há uma relação intrínseca entre as práticas pedagógicas e a avaliação. Desta forma, as práticas avaliativas não podem estar desvinculadas do processo de ensino e aprendizagem, tão pouco sinalizar o fim deste processo impregnada com o sentido de aprovar ou reprovar.

Neste contexto, atribuir significados positivos ao processo avaliativo e promover o fortalecimento do tripé família, escola e aluno deve ser uma prioridade no sistema educacional.

No que se refere às práticas pedagógicas a escola passou por uma série de modificações, metodológicas, filosóficas, tecnológicas e outras, que refizeram o seu perfil em termos de estrutura e organização, porém as formas de avaliar o aluno se mantêm com dificuldades de acompanhar esse processo dentro de uma perspectiva interativa e interventiva.

Nesta perspectiva, os planejamentos escolares devem objetivar descaracterizar os significados negativos estigmatizados para avaliação como: seletiva, exclusiva e quantificativa para denotar inclusão, reflexão e aprimoramento, na ótica da formação crítica e consciente do educando.

\section{HISTÓRICO DA AVALIAÇÃO}

O termo avaliar, pode ser utilizado em diversos contextos, seja escolar ou não. Partindo do conceito de avaliação é possível perceber que o ato de avaliar é uma constante na história da humanidade.

De acordo o dicionário Aurélio um dos conceitos de avaliação é "apreciar o merecimento; reconhecer a força”, desde os primórdios essa prática já era utilizada por tribos, como costumes e rituais para elevação do status de jovem para adulto. 
Dentro de uma visão ampla de educação que abrange as práticas sociais do sujeito em evolução, Brandão (2007) afirma que:

Educação é uma prática social (como a saúde pública, a comunicação social, o serviço militar) cujo fim é o desenvolvimento do que na pessoa humana pode ser aprendido entre os tipos de saber existentes em uma cultura, para a formação de tipos de sujeitos de acordo com as necessidades e exigências de sua sociedade, em um momento da história de seu próprio desenvolvimento. (BRANDÃO, 2007, p.73)

Somos seres históricos e as práticas avaliativas acompanharam o homem ao longo de sua história no compasso das suas necessidades, movidos pela necessidade de obtenção resultados. Para Aranha (2006) a avaliação não pode ser compreendida fora do contexto social histórico.

Em meados de 2.05a.c um Imperador Chinês, chamado Shun, para manter ou excluir seu corpo de oficias costumava avalia-los a cada triênio. Na Idade Antiga, Gregos e Espartanos faziam jogos e competições. Segundo Lima (2008) Sócrates, em Atenas examinava seus alunos através do exame oral, vale evidenciar que o termo "conheça te a ti mesmo" utilizado por ele, remetia a autoavaliação.

$\mathrm{Na}$ Idade Média, regida pela fé, surgi as escolas cristãs, direcionadas pelos monges de forma restrita. Onde, as práticas avaliativas eram através de dissertações orais. Para Souza (2005) os doutores medievais preparavam os caminhos da razão e abriram novas perspectivas para avaliação.

Para Aranha (2006) o período Moderno foi influenciado por aspectos humanísticos. Características estas vindas do renascimento com a exaltação e valorização do indivíduo. Fato que colaborou para mudança na visão de avaliação priorizando nas escolas, a música, o canto, a pintura e os jogos.

Com o surgimento da impressa, amplia-se a acessibilidade aos livros, escolas foram fundadas e bibliotecas abertas. Neste contexto e influências surge a Idade Moderna.

$\mathrm{Na}$ Idade Contemporânea, o sistema educacional tradicional sofre influências iluministas, através de algumas correntes pedagógicas. Neste sentido Lima (2008) questiona as práticas avaliativas contemporâneas, ao dizer que neste período surgiram várias correntes pedagógicas como a pedagogia libertadora a libertária e a crítica social dos conteúdos, porém a avaliação continua limitada a aplicação de provas. 
O termo "Avaliação institucional" teve seu parâmetro com o jovem educador Norte Americano, Ralph Tyler em 1934, que insatisfeito com os altos índices de reprovação do seu país propôs um método de ensino chamado "educação por objetivos".

Segundo Souza (2005), foi nos Estados Unidos, no século XIX que surgiu o termo avaliação. Foi a partir deste momento que houve a institucionalização da prova escrita. A Inglaterra, em 1702, foi o primeiro país a utilizar a prova escrita, devido ao número expressivo de alunos.

No Brasil, é possível destacar as práticas educacionais que influenciaram o sistema educacional brasileiro, através dos Jesuítas, os exames escolares, da forma como conhecemos hoje, foram sistematizados ao longo do século XVI e a primeira metade do século XVII.

Segundo Chaves (2003, p.14) “A Ratio studiorum dos jesuítas promulgada em 1559, resultante em mais de meio século de prática educativa, continha propostas e normas pedagógicas que davam a todas as escolas jesuítas uma configuração comum". Libâneo (2012) diz que:

$\mathrm{Na}$ Ratio Studiorum, há um capítulo específico há um capítulo específico sobre os exames escolares, [...]. Neste capítulo do documento, estão estabelecidos os deveres dos educadores e dos estudantes na realização dos exames, assim como as decisões pedagógicas a serem tomadas a partir deles, no sentido de aprovar ou reprovar o educando no que diz respeito ao aproveitamento dos estudos na classe em que se encontra. (LIBÂNEO, 2012, p. 436)

Sua forma de avaliar através de provas orais e exames são recursos que permanecem até os dias atuais, a função da avaliação era atribuição do mérito, os resultados condicionavam a promoção para as séries seguintes, premiações públicas e solenes ocorriam sempre que um aluno pleiteasse o nível estipulado como o ideal.

Resquícios destas práticas compensatórias permanecem nos dias atuais. Luckesi (2008) nos diz que:

Os Jesuítas (século XVI), nas normas orientação dos estudos escolásticos, seja nas classes inferiores ou nas superiores, ainda que definissem com rigor os procedimentos a serem levados em conta num ensino eficiente [...], tinham uma atenção especial com o ritual das provas e exames [...]. (2008, p. 22) 
No contexto brasileiro atual Luckesi (2008), afirma que "a avaliação da aprendizagem escolar no Brasil, hoje in genere, está a serviço de uma pedagogia dominante".

Sob a ótica do autor é possível inferir que as práticas avaliativas colaboram para manutenção da condição das camadas sociais, que sempre privilegia uma minoria.

Todos esses acontecimentos influenciaram as práticas avaliativas atuais e trazem reflexões acerca do seu sentido, significados e efetiva finalidade, potencializando as discussões sobre a forma de avaliar e o método utilizado.

\subsection{Avaliação no Sistema Educacional Brasileiro}

Até os anos 20 ainda não existia uma função "educadora" na sociedade, a educação servia a classe dominante. Segundo Romanelli (1983) a oferta da escola média, por exemplo, era incipiente, restringindo-se, praticamente a algumas iniciativas do setor privado.

O Ministério da Educação e Saúde foi criado em 1930, momento em que se criou o Sistema Nacional de Ensino. Em 1934 a constituição estabeleceu a necessidade de elaboração de um Plano Nacional de Educação. Dos anos 50 aos 90 muitos estudos e pesquisas nortearam a área de educação nas vertentes sociológicas, filosóficas, políticas e tecnológicas.

A criação da Lei 9.394/96 normatizou o sistema educacional, estabelendo diretrizes que visam disciplinar a educação escolar, promovendo mudanças significativas na educação básica, sinalizando o acesso a educação para todos. A LDB (Lei de Diretrizes e Bases da Educação Nacional) está amparada pela Constituição Federal (1988).

O ensino médio, objeto de estudo desta pesquisa, tem sua obrigatoriedade e gratuidade garantida no artigo 208, inciso II, da Constituição Federal e nos artigos 35 e 36 da LDB.

De acordo Libâneo (2012) a ideia de avaliação da aprendizagem chegou ao Brasil em fins dos anos 1960 com ênfase nos finais dos anos 1970. A expressão "exames escolares" foi abolida pela lei 5.692/71.

A expressão "avaliação" surge expressa com a LDB de 1996. Regulamentando a avaliação no sistema educacional brasileiro em seu Artigo 24, inciso: 
V - a verificação do rendimento escolar observará os seguintes critérios:

a) avaliação contínua e cumulativa do desempenho do aluno, com prevalência dos aspectos qualitativos sobre os quantitativos e dos resultados ao longo do período sobre os de eventuais provas finais;

b) possibilidade de aceleração de estudos para alunos com atraso escolar;

c) possibilidade de avanço nos cursos e nas séries mediante verificação do aprendizado;

d) aproveitamento de estudos concluídos com êxito;

e) obrigatoriedade de estudos de recuperação, de preferência paralelos ao período letivo, para os casos de baixo rendimento escolar, a serem disciplinados pelas instituições de ensino em seus regimentos; (BRASIL, 1996)

As inquietações no que se referem a avaliação são frequentes nas escolas principalmente no ensino médio. Benjamin Bloom (1983) afamado pesquisador da área de aprendizagem, classifica a avaliação em três categorias: diagnóstica, formativa e somativa.

\subsubsection{Avaliação Diagnóstica:}

O próprio nome nos remete ao verbo de ação diagnosticar, que de acordo 0 dicionário Aurélio significa "exame; encontrar a razão ou natureza de determinado fato ou estado".

Suscitando este conceito para o campo educacional, o diagnóstico fornece ao educador informações sobre os educandos que poderão nortear suas atividades pedagógicas e potencializar as práticas educativas em função do desenvolvimento da aprendizagem.

Luckesi (2007, p. 5) diz que: "Avaliar é o ato de diagnosticar uma experiência, tendo em vista reorientá-la para produzir o melhor resultado possível; por isso, não é classificatória nem seletiva, ao contrário, é diagnóstica e inclusiva".

Este processo diagnóstico se caracteriza como uma avaliação e não como um julgamento. Neste contexto, Luckesi (2000) destaca a importância da compreensão dessa diferença:

Para compreender isso, importa distinguir avaliação de julgamento. $O$ julgamento é um ato que distingue o certo do errado, incluindo o primeiro e excluindo o segundo. A avaliação tem por base acolher uma 
situação, para, então (e só então), ajuizar a sua qualidade, tendo em vista dar-lhe suporte de mudança, se necessário. A avaliação, como ato diagnóstico, tem por objetivo a inclusão e não a exclusão; a inclusão e não a seleção - que obrigatoriamente conduz à exclusão. (LUCKESI, 2000, p.172)

Sob esta ótica, a avaliação diagnóstica serve de subsídio para a avaliação formativa. Juntas, elas concebem a aprendizagem como um processo e utilizam a avaliação como um dos instrumentos inerentes as práticas pedagógicas.

\subsubsection{Avaliação Formativa}

Esta modalidade de avalição ocorre durante o processo de aprendizagem, primando pelo efetivo ensino, que se manifesta à medida que o aluno vai identificando seus erros e pontos que precisam ser aprimorados.

Contribui também com o professor, ao proporcionar a identificação das deficiências e assim oportunizar o planejamento do seu trabalho didático com possibilidades de reestruturação da sua prática pedagógica. Na concepção de Perrenoud (1999):

A avaliação formativa é toda prática de avaliação contínua que pretenda melhorar as aprendizagens em curso, contribuindo para o acompanhamento e orientação dos alunos durante todo o seu processo de formação. É formativa toda a avaliação que ajuda o aluno a aprender e a se desenvolver, que participa da regulação das aprendizagens e do desenvolvimento no sentido de um projeto educativo. (PERRENOUD, 1999, p. 182)

Loch (2000) preconiza essa visão da avaliação formativa numa perspectiva processual ética, consciente e reflexiva de todos os envolvidos ao afirmar que:

Avaliar não é dar notas, fazer médias, reprovar ou aprovar os alunos. Avaliar, numa nova ética é sim avaliar participativamente no sentido da construção, da conscientização busca da auto crítica, auto conhecimento de todos os envolvidos no ato educativo, investindo na autonomia, envolvimento, compromisso e emancipação dos sujeitos. (LOCH, 2000, p. 31)

Neste sentido, o feedback se torna um elemento regulamentador do processo ensino e aprendizagem, propiciando os ajustes necessários dentro de um processo interativo e reflexivo. 
Dessa forma, é possível inferir que, a avaliação formativa é dialógica e sua função se volta para o ensino através da própria avaliação que ao invés de classificar, excluir ou mensurar, tem o poder de ensinar através dos erros e dificuldades. Neste contexto o poder transformador da avaliação se materializa.

\subsubsection{Avaliação Somativa}

Também conhecida como classificatória, representa o modelo tradicional de educação e está presente no sistema educacional brasileiro, nas escolas ela se caracteriza nos diversos instrumentos avaliativos utilizados como provas e testes com o intuito de classificar, valorizando o aspecto quantitativo.

Neste sentido, Aquino (2009) sobre as características da avaliação classificatória assevera que:

[...] indica uma simples verificação quantitativa daquilo que o aluno aprendeu dos conteúdos abordados; avalia-se o resultado final, e não o processo; somente são levados em consideração os aspectos técnicos da avaliação. (AQUINO, 2009, p.4)

De acordo o autor, neste processo quantitativo a ênfase está na quantidade de conteúdos e acertos, e não no processo de construção da aprendizagem do educando.

\section{Avaliação Interna e Externa}

Conforme Luckesi, (2001, p.28) “a avaliação não se dá nem se dará num vazio conceitual, mas sim dimensionada por um modelo teórico de mundo e de educação, traduzido em prática pedagógica”. Em consonância Freitas assevera que:

[...] postulamos a existência de três níveis integrados de avaliação da qualidade de ensino: avaliação em larga escala em redes de ensino (realizadas no pais, Estados ou municípios); avaliação institucional da escola (feita em cada escola pelo seu coletivo) e a avaliação da aprendizagem em sala de aula, sob responsabilidade do professor. (DE FREITAS, 2009, P. 10)

Diante das falas dos autores é possível perceber que a teoria rege a prática pedagógica tanto no âmbito governamental, institucional ou mesmo individual. 
Nessa perspectiva, os objetivos e metas precisam estar bem definidos, assim como os resultados devem ser observados e passivos a intervenções em todos os níveis da aprendizagem quando necessário.

\subsection{Avaliação Interna}

$O$ ato de avaliar fornece dados, que permitem verificar diretamente o nível de aprendizagem dos alunos, e também, indiretamente determinar a qualidade do processo de ensino.

Dentro dessa linha Ozório (2002, p.36) diz que "Ao avaliar o progresso de seus alunos na aprendizagem, o professor pode obter informações valiosas sobre seu próprio trabalho".

Ferreira (2002, p.11) relata que "Sendo a avaliação um ato tão presente no diaa-dia da escolar, há necessidade de um melhor entendimento do que esta ação representa no contexto educativo".

Nesse sentido a avaliação interna pode ser considerada, o termômetro da aprendizagem para os alunos, professores e para a própria instituição de ensino, envolvendo as práticas e ações cotidianas.

Nesta vertente, Basso (2009, p. 7) afirma que "ela [a avaliação] deva ocorrer concomitante ao processo de ensino, ou seja, que a avaliação não seja uma parte separa do processo e sim, que ocorra ao mesmo tempo".

De acordo com os Parâmetros Curriculares Nacionais (1988), a avaliação informa ao professor o que foi aprendido pelo aluno, fazendo-o refletir sobre a eficácia de sua prática educativa e orientando-o para intervenções necessárias.

As OCNEM (Orientações Curriculares Nacionais para o Ensino Médio) permeiam o debate sobre avaliação da aprendizagem e destaca seu papel ao afirmar que "a avaliação formativa, contínua, de acompanhamento, que fornece subsídios valiosos para o professor e para os alunos, deve ser privilegiada" (OCNEM, 2006. p.143).

Nesta perspectiva, a avaliação deve ser compreendida como um conjunto de ações direcionadas sob o propósito de adquirir informações pertinentes sobre 0 aprendizado do aluno, assim pressupõe-se que a avaliação interna acontece no âmbito escolar especificamente na sala de aula objetivando o educando. 


\subsection{Avaliação externa}

A avaliação externa também conhecida como avaliação de larga escala, se caracteriza como um dos principais instrumentos do governo para elaboração e implementação de políticas públicas educacionais.

Essas avaliações informam sobre os resultados educacionais de escolas e redes de ensino a partir do desempenho em testes e provas padronizadas que verificam se estes aprenderam o deveriam ter aprendido, permitindo inferências sobre o trabalho educativo das escolas e rede de ensino. (BLASIS, FALSARRELA e ALAVARSE, 2013, p.12)

Segundo o INEP (Instituto Nacional de Estudos e Pesquisas Educacionais Anísio Teixeira) "Além disso, realizar avaliações e divulgar seus resultados é uma forma de o poder público prestar contas da sua atuação à sociedade em geral, proporcionando uma visão clara dos resultados do processo de ensino e das condições em que é desenvolvido".

Assim, as avaliações de larga escala, além de nortear as políticas educacionais, podem refletir nas práticas pedagógicas utilizadas nas escolas e possibilitar discussões ao estabelecer uma relação dialógica com as avaliações internas.

É importante reconhecer que a avaliação externa não termina com a divulgação dos resultados das provas e indicadores. Ela continua à medida que envolve a sociedade, escolas, comunidades e poder público nos debates sobre esses resultados e, a partir disso, abrindo caminho tanto para adensar e dialogar com as avaliações internas realizadas no âmbito das escolas (do projeto pedagógico e da ação educativa), quanto no âmbito das secretarias de educação (das diretrizes da política educacional). (BLASIS, FALSARELLA e ALAVARSE, 2013, p.39).

De acordo o Portal da Educação (2018), as avaliações externas têm como característica uma matriz de avaliação e o emprego de provas padronizadas para que sejam obtidos a interpretação dos resultados para efetuar comparação entre redes e escolas para definir políticas públicas.

Conhecer e reconhecer os resultados desta avaliação é necessário e importante para os professores e gestores educacionais. O Ministério da Educação e 
Cultura (MEC) através do Instituto Nacional de Estudos e Pesquisas Educacionais Anísio Teixeira (INEP), elabora e aplica avaliações de larga escala.

\title{
2.3 Concepção da avaliação numa perspectiva Humanizada
}

Partindo do pressuposto que princípios básicos para a humanidade como igualdade, liberdade e educação são direitos assegurados na legislação brasileira (Constituição Federal de 88, LDB, 9394/96 e ECA), a escola sendo uma instituição social deve ser o local onde exercício da cidadania possa imperar.

No prisma do homem como ser integrado ao mundo como ser social e ativo Freire assevera que:

\begin{abstract}
A educação como prática da liberdade, ao contrário daquela que é prática da dominação, implica na negação do homem abstrato, isolado, solto, desligado do mundo, assim também na negação do mundo como uma realidade ausente dos homens. (FREIRE, 1987, p.40)
\end{abstract}

Com isso, é possível denotar o homem como um ser concreto, ativo e capaz de transformar o mundo que o cerca. Não alheia a essa realidade, no âmbito escolar a prática de avaliar, deve ter uma postura metodológica que represente o indivíduo como ser social.

Nesse sentido LUCKESI (2005), afirma que está ocorrendo uma "prática de avaliação da aprendizagem escolar - ingênua e inconsciente - como se ela não estivesse a serviço de um modelo teórico de educação".

Esta postura aponta uma compreensão equivocada da função social da escola, desconsiderando seu objetivo maior que é o ser social, ativo, crítico e transformador. Nesse sentido Luckesi afirma que:

Estando a atual prática de avaliação educacional escolar a serviço de um entendimento teórico conservador da sociedade e da educação, para propor o rompimento dos seus limites, que é o que procuramos fazer, temos de necessariamente situá-la num outro contexto pedagógico, ou seja, temos de, opostamente, colocar a avaliação escolar a serviço de uma pedagogia que entenda e esteja preocupada com a educação como mecanismo de transformação social. (LUCKESI, 2005, P.28) 
Neste contexto, os profissionais da educação precisam ter delineados o entendimento acerca da sociedade a qual atuam e do método que a ela se vai aplicar. Conforme Luckesi, (2005, p.28) "a avaliação não se dá nem se dará num vazio conceitual, mas sim dimensionada por um modelo teórico de mundo e de educação, traduzido em prática pedagógica". De acordo Freire:

O educador, que aliena a ignorância, se mantem em posições fixas, invariáveis. Será sempre o que sabe, enquanto os educandos serão sempre os não sabem. A rigidez destas posições nega a educação e o conhecimento como um processo de busca. (FREIRE, 1987, p.34)

$\mathrm{O}$ autor dialoga também sobre os educadores que tem por objetivo a domesticação do estudante e aqueles educadores que pretendem a humanização dos educandos. O primeiro grupo de pedagogias está preocupado com a reprodução e conservação da sociedade e, o segundo, voltado para as perspectivas e possibilidades de transformação social (LIBÂNEO, 1984).

Como são duas vertentes diferentes, as práticas de avaliação também se distinguem, sendo uma voltada para avaliação institucional e outra para a avaliação da aprendizagem. Para Luckesi:

\begin{abstract}
A prática da avaliação escolar, dentro do modelo liberal conservador, terá de, obrigatoriamente, ser autoritária, pois, esse caráter pertence a essência dessa perspectiva de sociedade, que exige controle e enquadramento dos indivíduos nos parâmetros previamente estabelecidos de equilíbrio social, seja pela utilização de coações explícitas seja pelos meios sub-reptícios das diversas modalidades de propaganda ideológica. A avaliação educacional será, assim, um instrumento disciplinador não só das condutas cognitivas como também das sociais, no contexto da escola. (LUCKESI, 2005, p. 32)
\end{abstract}

Diante do exposto é possível perceber que praticas avaliativas, baseadas em moldes autoritaristas, versam uma pedagogia conservadora, enquanto uma prática avaliativa democrática busca a transformação social e reflete os direitos e anseios dos seres humanos já expressados na legislação.

Nesta perspectiva, a avaliação não pode ser praticada de forma classificatória, Luckesi, (2005) nos diz que "a atual prática de avaliação escolar estipulou como função do ato de avaliar a classificação e não o diagnóstico como deveria ser construtivamente". O Autor alerta que: 
[...] O educando como sujeito humano é histórico; contudo, julgado e classificado, ele ficará, para o resto da vida, do ponto de vista do molde escolar vigente, estigmatizado, pois as anotações e registros permanecerão, em definitivo nos arquivos e nos históricos escolares, que se transformam em documentos legalmente definidos. (LUCKESI, 2005, p.35)

Muitas vezes, a avaliação é praticada representando o fim do processo de aprendizagem, Luckesi nos diz que "de fato, o momento da avaliação deveria ser um "momento de fôlego" na escalada para, em seguida, ocorrer a retomada da marcha de forma mais adequada, e nunca um ponto definitivo de chegada, especialmente quando o objeto da ação avaliativa é dinâmico como, no caso, a aprendizagem". (LUCKESI, 2005, p. 34-35)

\subsection{0 conselho de classe numa perspectiva democrática}

Muitos autores falam em "Gestão Democrática" dentro das escolas, baseada sempre na cooperação, transparência e políticas educacionais vinculadas a um ensino de qualidade.

Dentro desse debate Luck (2001) assevera que os diretores participativos se baseiam no conceito da autoridade compartilhada, cujo poder é delegado aos representantes da comunidade escolar e as responsabilidades são assumidas por todos.

De acordo a LDB (Lei n. 9.394/96), as instituições públicas que ofertam a Educação Básica devem ser administradas com base no princípio da Gestão Democrática.

A Portaria no 10228/2016 sob a Instrução normativa 002/2016 que orienta as unidades de ensino da rede Estadual da Bahia quanto a aplicação dos procedimentos avaliativos conceitua o conselho de classe como:

O conselho de classe é um órgão colegiado de natureza consultiva e deliberativa em assuntos didáticos, pedagógicos e disciplinares fundamentado no Projeto Político Pedagógico da unidade escolar e nos marcos regulatórios vigentes (Portaria 6562/2016 Art.12). Cabe à unidade escolar realizar o conselho de classe para a avaliação e os encaminhamentos que se fizerem necessários sobre o aproveitamento individual e/ou coletivo dos (das) estudantes. (BRASIL, 2016) 
Isto posto, o trabalho deve ser conduzido de forma crítica e reflexiva entre todos os membros. Nesta perspectiva Dalben afirma que:

$\mathrm{Na}$ Gestão Democrática, todos são chamados a pensar, avaliar e agir coletivamente, diante das necessidades apontadas pelas relações educativas, percorrendo um caminho que se estrutura com base no diagnóstico das dificuldades e necessidades e do conhecimento das possibilidades do contexto. Nesse trajeto a equipe de profissionais vai traçando os objetivos que nortearão a construção das ações cotidianas, encontrando sua forma original de trabalho. Essa travessia permite a cada escola a construção coletiva de sua identidade. (DALBEN, 2004, p.56)

Diante do exposto, é possível refletir sobre a escola como um espaço coletivo e repleto de diversidade, nela encontramos pessoas de culturas, hábitos, religiões e orientações distintas.

\subsection{Reunião de pais como uma prática avaliativa}

O verbo educar provém do latim educare. De acordo o dicionário Aurélio a palavra educar significa: dar ou oferecer (a alguém) conhecimentos e atenção especial para que possa desenvolver suas capacidades intelectuais, morais e físicas.

Este conceito nos conduz a pensar sobre a diversidade do significado do verbo educar no sentido mais amplo da palavra, que compreende a formação do indivíduo dentro de uma perspectiva que culmine no desenvolvimento da sua autonomia face a situações sociais diversas.

Nesta abordagem, família e escola trilham o mesmo caminho, no intuito de proporcionar uma aprendizagem efetiva, significativa e transformadora para o sujeito, que é ao mesmo tempo aluno para a instituição escolar e filho para a instituição familiar. Logo, estabelecer uma relação de confiança e coparticipação se faz necessário.

De acordo a LDB (Lei 9.39496) em seu Art.1ํ - A Educação abrange os processos formativos que se desenvolvem na vida familiar, na convivência humana, no trabalho, nas instituições de ensino e pesquisa, nos movimentos sociais e organizações da sociedade civil e nas manifestações culturais.

A constituição Federal de 1988, em seu Artigo 205 nos diz que "a educação é um direito de todos e dever do Estado e da Família". O Estatuto da Criança e do 
Adolescente (ECA) em seu artigo 4ํㅜㄹ reitera o dever da família na formação educacional dos filhos:

"É dever da família, da comunidade, da sociedade em geral e do Poder Público assegurar com absoluta prioridade, a efetivação dos direitos referentes à saúde, à alimentação, à educação, ao esporte, ao lazer, à profissionalização, à cultura, à liberdade e a convivência familiar e comunitária". (BRASIL, 1990, p.20),

A legislação evidencia a inclusão e a participação da família no contexto escolar. A família é a instituição mais próxima que a instituição escolar tem do estudante, daí a necessidade de engajá-la no processo de aprendizagem, visto que, o pleno desenvolvimento do educando é um propósito comum a ambas.

É preciso que os pais se apropriem dos seus deveres na educação dos filhos. Para Sandi:

A família é o berço da formação de regras, princípios e valores, outras instituições assim como a escola, possuem também papel muito importante nesta formação moral, a escola se organizando de forma democrática, oportunizando uma vivência cidadã. Dessa forma, promovem o nascimento crescimento do respeito mútuo e o desenvolvimento da autonomia, ingrediente para formação. (SANDI, 2008, p.34)

Escola e família devem andar juntas, exemplificando de forma prática para os alunos/filhos que é possível dar opiniões, sugestões, debater sobre assuntos e problemas diversos prezando sempre o respeito, neste sentido, Paro (2007), afirma que o diálogo é um fator importante entre a família e escola.

As reuniões de pais e mestres deveriam ocorrer no início do ano letivo com objetivos definidos pela instituição, mas costumam acontecer ao final do fechamento de cada unidade letiva. Isso leva aos pais a ideia errônea de que o encontro será para discutir sobre "aprovação e reprovação" ou "bom e mau comportamento".

\section{METODOLOGIA}

A pesquisa realizada foi de cunho qualitativa, quantitativa, bibliográfica e exploratória, com análise documental e estudo de campo. De acordo Gil (1999, p.26) 
a investigação científica depende de um "conjunto de procedimento intelectuais e técnicos".

O cunho qualitativo se caracterizou por estarmos em contato direto com os sujeitos da pesquisa, objetivando responder questionamentos subjetivos acerca das suas expectativas, anseios e perspectivas dentro do processo avaliativo.

Segundo Minayo (2010, p. 21) "a pesquisa qualitativa responde a questões muito particulares. Ela se preocupa com um nível de realidade que não pode ser quantificada". Portanto, o trabalho em questão vem de encontro a fala da autora.

Dados quantitativos foram utilizados de forma subjetiva, para André (2004) uma pesquisa não se descaracteriza como tal por fazer uso de dados quantificadores.

Neste sentido Minayo (2001, P. 22) afirma que "o conjunto de dados quantitativos e qualitativos não se opõem. Ao contrário, se complementam, pois, a realidade abrangida por eles interage dinamicamente, excluindo qualquer dicotomia".

A técnica de pesquisa bibliográfica e exploratória, ocorreu considerando que houve a leitura e análise de documentos que abordavam as práticas avaliativas dentro da escola observada como: o PPP, Portarias, Normas e Resoluções que regem a dinâmica escolar. Houve também o levantamento bibliográfico de autores que abordaram a temática avaliação dentro de uma perspectiva significativa e formativa.

Nesta perspectiva visando o sujeito como ator dentro do processo de construção do conhecimento o método utilizado foi o fenomenológico, preconizado por Husserl.

\section{CONSIDERAÇÕES FINAIS}

Com base nos dados da pesquisa, nota-se que os aspectos qualitativos, muitas vezes, não condizem com as notas expressas nos boletins informativos de rendimento escolar. Para o questionamento "O seu boletim de notas corresponde ao seu aprendizado?" 55\% dos discentes responderam que sim, seguida de $38 \%$ que disseram nem sempre e, 07\% afirmaram que não.

Na perspectiva de uma prática avaliativa processual onde as responsabilidades são compartilhadas, os estudantes foram questionados sobre o que eles fazem quando não atingem resultados satisfatórios nas avaliações. $62 \%$ afirmaram procurar estudar mais e tentar recuperar a nota na próxima unidade, 33\% disseram ficar preocupados e apenas $5 \%$ afirmaram que observam onde erraram e tentam aprender 
mesmo não valendo mais nota. Estes dados demonstram que a valorização da nota, ainda é uma constante no ensino médio.

Evidenciou-se a reuniões de pais como uma prática avaliativa que não exprime significados notáveis e apropriados pelos pais e alunos, tendo sua importância minimizada ou mesmo ignorada dentro do processo de ensino e aprendizagem, visto que, ao serem questionados sobre o nível de participação dos pais nas reuniões escolares, apenas $14 \%$ dos alunos disserem sempre, $12 \%$ quase nunca, $34 \%$ nunca e $40 \%$ às vezes.

As respostas para as questões abordando o conselho de classe, evidenciaram que $95 \%$ dos estudantes reconhecem o conselho como forma de avaliação, mas a maior parte deles cerca de 55\% afirmaram desconhecer os critérios utilizados neste processo, o que denota a necessidade de transparência no processo avaliativo.

Questionados sobre palavras que exprimem significados para avaliação, as respostas dos docentes variaram entre "feedback, termômetro, reflexão, retorno, oportunidade e aprendizagem". O mesmo questionamento foi direcionado aos os alunos que responderam "tensão, preocupação, medo, hora da verdade, dificuldades, tudo ou nada". As divergências nas respostas evidenciam a necessidade de ações dialógicas que descaracterizem conceitos negativos e estigmatizados para a avaliação.

\section{CONCLUSÃO}

O presente estudo constatou que a questão da pesquisa é extremamente complexa, visto que não referencia apenas o aluno, mas também os pais, professores e a instituição escolar.

Compreender os conceitos e os aspectos legais que regem as práticas avaliativas permitiu perceber que a avaliação sob a ótica do sistema educacional é extremamente abrangente e em alguns aspectos divergente. Abrangente porque visa a formação integral do indivíduo para atuação na sociedade de forma crítica e consciente, mas divergente porque condiciona um juízo mensurável sobre a formação que a mesma legislação assegura como um direito.

Evidenciou-se que para haver uma aprendizagem efetiva, que agregue significados positivos para todos os envolvidos é necessário que as práticas avaliativas ocorram de forma ética e coerente, onde as ações e responsabilidades 
sejam compartilhadas por todos, evitando assim, que a transferência do sentimento de "culpa" faça parte do resultado do processo avaliativo.

\section{REFERÊNCIAS}

BRANDÃO, C.R. O que é educação. Editora Brasiliense, coleção primeiros Passos. São Paulo, 2007.

BRASIL. Ministério da Educação. Lei de Diretrizes e Bases da Educação 9.394/96. Brasília. MEC, 1996.

Estatuto da Criança e do Adolescente 8069/90. Brasília. MEC 2004.

Constituição Federal. Brasília: Senado Federal, 1988.

ESTEBAN, M. T. A Avaliação no Cotidiano Escolar. In: ESTEBAN, M.T. (org.) Avaliação: uma prática em busca de novos sentidos. Rio de Janeiro, DP\&A Editora, pp.7-28, 1999.

DALBEN, Â. I. L. de F. Trabalho escolar e conselho de classe. 4. ed. Campinas: Papirus, 1996. (Coleção magistério: formação e trabalho pedagógico).

Conselho de Classe e avaliação - perspectivas na gestão pedagógica da escola 3. ed. Campinas: Papirus, 2006. (Coleção magistério: formação e trabalho pedagógico).

GARCIA, R. P. M. Avaliação da aprendizagem na educação a distância na perspectiva comunicacional. Cruz das Almas/ BA: UFRB, 2013.

FERREIRA, L. M. S. Retratos da avaliação: conflitos, desvirtuamentos e caminhos para superação. Porto Alegre: Mediação, 2002.

Pedagogia do oprimido. 47. ed. Rio de Janeiro: Paz e Terra, 2005.

HOFFMAN, J. Avaliação mito e desafio: uma perspectiva construtiva. 39. ed. Porto Alegre: Mediação, 2008. 
Avaliação mito e desafio: uma perspectiva construtivista. 41. ed. Porto Alegre: Mediação, 2011.

LUCKESI, C.C. Avaliação da aprendizagem escolar. São Paulo: Cortez, 2000.

Avaliação da aprendizagem escolar: estudos e proposições. 17 ed. São Paulo: Cortez, 2005.

Avaliação da aprendizagem escolar: estudos e proposições. 19. ed. São Paulo: Cortez, 2008.

LIBÂNEO, J. C. Organização e gestão da escola: teoria e prática. 4. ed. Goiânia: Alternativa, 2001.

MINAYO, M. C. de S. (org.). Pesquisa Social. Teoria, método e criatividade. 18 ed. Petrópolis: Vozes, 2001.

MORETO, V. P. Prova: um momento privilegiado de estudo, não um acerto de contas. 8. ed. Rio de Janeiro: Lamparina, 2008.

PERRENOUD, P. Avaliação: da excelência à regulação das aprendizagens, entre duas lógicas. Porto Alegre: Artmed, 1999.

PARO V. H. Qualidade do ensino: a contribuição dos pais. São Paulo: Xamã, 2007.

PAROLIM, I. As dificuldades de aprendizagem e as relações familiares. Fortaleza, 2003.

PIAGET, J. Para onde vai à educação? Rio de Janeiro: José Olímpio, 2007.

VASCONCELLOS, C.S. Para onde vai o professor? Resgate do professor como sujeito de transformações. São Paulo: Libertad, 2001.

Avaliação da aprendizagem: Práticas de mudanças por uma práxis transformadora. 5a . ed. Cadernos Pedagógicos do Libertad. Vol. 6. São Paulo: Libertad, 2003. 